\title{
Coincidence Points in Ordered Cone Metric Spaces
}

\author{
Kasani Prudhvi \\ Department of Mathematics, University College of Science, Saifabad, Osmania University, Hyderabad, Telangana State, India \\ *Corresponding Author: prudhvikasani@rocketmail.com
}

Copyright (C) 2014 Horizon Research Publishing All rights reserved.

\begin{abstract}
In this paper, we prove a coincidence point theorem for two self-mappings in an ordered cone metric spaces, without using normality and continuity . Our result extends and improves some recent results existing in the literature.
\end{abstract}

Keywords Coincidence Point, Cone Metric Space, Ordered Sets, Weakly Decreasing Maps of Type A

\section{Introduction and Preliminaries}

In 2007, Huang and Zhang [4] introduced the concept of cone metric space by substituting an ordered Banach space for real numbers it is generalization of the metric space. And proved fixed point theorems of contractive type mappings over cone metric spaces. Later on, many authors generalized their fixed point theorems to different types of contraction mappings in cone metric spaces (see, e.g. [1,2, 3, 6, 7]). Recently, Wasfi Shatanawi [8] obtained some coincidence point results in cone metric spaces. In this paper, we prove a coincidence point theorem for two self mappings in an ordered cone metric spaces, without using normality and continuity, which extends and improves the results of [8].

Throughout this paper $\mathrm{B}$ is a real Banach space, $\theta$ denotes zero element of $\mathrm{B}$. [4].

The following definitions are due to Huang and Zhang

Definition 1.1[4] Let $B$ be a real Banach Space and $P$ a subset of $B$.The set $P$ is called a cone if and only if:

(a). $\mathrm{P}$ is closed, non-empty and $\mathrm{P} \neq\{\theta\}$;

(b). a,b $\in R, \mathrm{a}, \mathrm{b} \geq 0, \mathrm{x}, \mathrm{y} \in P$ implies ax $+\mathrm{by} \in P$;

(c). $\mathrm{x} \in \mathrm{P}$ and $-\mathrm{x} \in P$ implies $\mathrm{x}=\theta$.

Definition 1.2([4]).Let $P$ be a cone in a Banach Space B, define partial ordering ' $\preccurlyeq$ ' with respect to $P$ by $x \preccurlyeq y$ if and only if $\mathrm{y}-\mathrm{x} \in P$.We shall write $\mathrm{x} \prec \mathrm{y}$ to indicate $\mathrm{x} \preccurlyeq \mathrm{y}$ but $\mathrm{x} \neq \mathrm{y}$ while $\mathrm{x}<<\mathrm{y}$ will stand for $\mathrm{y}-\mathrm{x} \in$ Int $\mathrm{P}$, where Int $\mathrm{P}$ denotes the interior of the set $\mathrm{P}$. This Cone $\mathrm{P}$ is called an order cone. It can be easily shown that $\lambda \operatorname{int}(\mathrm{P}) \subseteq$ int $(\mathrm{P})$ for all $\lambda \in \mathbb{R}^{+}$.

Definition 1.3([4]). Let $\mathrm{B}$ be a Banach Space and $\mathrm{P} \subset \mathrm{B}$ be an order cone. The order cone $\mathrm{P}$ is called normal if there exists $\mathrm{K}>0$ such that for all $\mathrm{x}, \mathrm{y} \in \mathrm{B}, \theta \preccurlyeq x \preccurlyeq y$ implies $\|\mathrm{x}\| \leq \mathrm{K}\|\mathrm{y}\|$.

The least positive number $\mathrm{K}$ satisfying the above inequality is called the normal constant of $\mathrm{P}$.

Definition 1.4([4]).Let $X$ be a nonempty set of $B$.Suppose that the map d: $X \times X \rightarrow B$ satisfies:

(d1). $\theta<\mathrm{d}(\mathrm{x}, \mathrm{y})$ for all $\mathrm{x}, \mathrm{y} \in X$ and $\mathrm{d}(\mathrm{x}, \mathrm{y})=\theta$ if and only if $\mathrm{x}=\mathrm{y}$;

(d2). $d(x, y)=d(y, x)$ for all $x, y \in X$;

(d3). $d(x, y) \preccurlyeq d(x, z)+d(y, z)$ for all $x, y, z \in X$

Then $\mathrm{d}$ is called a cone metric on $\mathrm{X}$ and $(\mathrm{X}, \mathrm{d})$ is called a cone metric space.

Definition 1.5([4]).Let $(\mathrm{X}, \mathrm{d})$ be a cone metric space .We say that $\left\{\mathrm{x}_{\mathrm{n}}\right\}$ is

(i) a Cauchy sequence if for every $\mathrm{c}$ in $\mathrm{B}$ with $\mathrm{c}>>\theta$, there is $\mathrm{N}$ such that for all $\mathrm{n}, \mathrm{m}>\mathrm{N}$, $\mathrm{d}\left(\mathrm{x}_{\mathrm{n},} \mathrm{x}_{\mathrm{m}}\right)<<\mathrm{c}$;

(ii) a convergent sequence if for any $\mathrm{c}>>$ $\theta$,there is an $\mathrm{N}$ such that for all $\mathrm{n}>\mathrm{N}$, $\mathrm{d}\left(\mathrm{x}_{\mathrm{n},} \mathrm{x}\right)<<\mathrm{c}$, for some fixed $\mathrm{x}$ in $\mathrm{X}$.

We denote this $\mathrm{x}_{\mathrm{n}} \rightarrow \mathrm{x}($ as $\mathrm{n} \rightarrow \infty)$

The space $(\mathrm{X}, \mathrm{d})$ is called a complete cone metric space if every Cauchy sequence is convergent.

The concept of weakly decreasing maps type A introduced by W. Shatanawi [8].

Definition 1.6([8]).Let $(X, \sqsubseteq)$ be partially ordered set and let $f, T: X \rightarrow X$ be two maps. We say that $f$ is weakly decreasing type $A$ with respect to Tif the following conditions hold:

(i). For all $\mathrm{x} \in \mathrm{X}$, we have that $\mathrm{f} \mathrm{x} \sqsubseteq$ fy for all $\mathrm{y} \in \mathrm{T}^{-1}(\mathrm{fx})$.

(ii). $\mathrm{TX} \subseteq \mathrm{fX}$.

Definition 1.7([5]).Let $(X, d)$ be a cone metric space and $\mathrm{f}, \mathrm{g}: \mathrm{X} \rightarrow \mathrm{X}$ be two self-maps. The pair $\{\mathrm{f}, \mathrm{g}\}$ is said to be compatible if, for an arbitrary sequence $\left\{\mathrm{x}_{n}\right\} \subset \mathrm{X}$ such that

$\lim _{n \rightarrow \infty} f x_{n}=\lim _{n \rightarrow \infty} g x_{n}=\mathrm{t} \in \mathrm{X}$, and for arbitrary $\mathrm{c} \in$ int $(\mathrm{P})$, there exists $\mathrm{n}_{0} \in \mathbb{N}$ such that $\mathrm{d}\left(\mathrm{fgx}_{\mathrm{n}}\right.$, 
$\left.\mathrm{gfx}_{\mathrm{n}}\right)<<\mathrm{c}$ whenever $\mathrm{n}>\mathrm{n}_{0}$. It is said to be weakly compatible if $\mathrm{fx}=\mathrm{gx}$ implies $\mathrm{fgx}=\mathrm{gfx}$.

Definition 1.8([1]).For the mapping $\mathrm{f}, \mathrm{g}: \mathrm{X} \rightarrow \mathrm{X}$. If $\mathrm{w}=$ $\mathrm{fz}=\mathrm{gz}$ for some $\mathrm{z}$ in $\mathrm{X}$, then $\mathrm{z}$ is called a coincidence point of $f$ and $g$ and $w$ is called a point of coincidence of $f$ and $g$.

\section{The Main Results}

In this section, we prove a coincidence point theorem for two self mappings in ordered cone metric spaces, without using normality and continuity. Our result extends and improves the results of [8].

The following Theorem is extend and improves Theorem 2.3 of [8].

Theorem 2.1. Let $(X$, ㄷ) be partially ordered set and $(X, d)$ be a cone metric space over a solid cone $P$. Let $f, T: X \rightarrow X$ be two self maps such that

$d(T x, T y) \leqslant a_{1} d(f x, f y)+a_{2} d(f x, T x)+a_{3} d(f y, T y)+a_{4} d(f$ $\mathrm{x}, \mathrm{Ty})$

for all $\mathrm{x}, \mathrm{y} \in \mathrm{X}$ for which $\mathrm{fx}$ and fy are comparable. Assume that $\mathrm{f}$ and $\mathrm{T}$ satisfy the following conditions:

(i). If $\left\{\mathrm{x}_{\mathrm{n}}\right\}$ is a non - increasing sequence in $\mathrm{X}$ with respect to $\subseteq$ such that $x_{n} \rightarrow x$ as $n \rightarrow+\infty$, then $x_{n} \sqsupseteq x$ for all $\mathrm{n} \in \mathrm{N}$.

(ii). $\mathrm{f}$ is weakly decreasing type $\mathrm{A}$ with respect to $\mathrm{T}$.

(iii). $\mathrm{fX}$ is complete subspace of $\mathrm{X}$.

If $a_{1}, a_{2}, a_{3}, a_{4}$ are non-negative real numbers with $a_{1}+a_{2}+$ $\mathrm{a}_{3}+\mathrm{a}_{4} \in[0,1)$, then $\mathrm{f}$ and $\mathrm{T}$ have a coincidence point in $\mathrm{X}$, that is there exists a point $u \in X$ such that $f u=T u$.

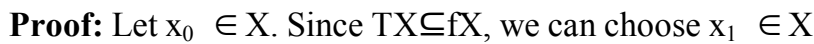
such that $\mathrm{Tx}_{0}=\mathrm{fx}_{1}$. Also since $\mathrm{TX} \subseteq \mathrm{fX}$

We can choose $x_{2} \in X$ such that $T x_{1}=f x_{2}$. Continuing this process, we can construct a sequence $\left\{\mathrm{x}_{\mathrm{n}}\right\}$ in $\mathrm{X}$ such that $T x_{n}=f x_{n+1}$. Since $x_{n} \in T^{-1}\left(f x_{n+1}\right), n \in N$, then by using the assumption that $\mathrm{f}$ is weakly decreasing of type $\mathrm{A}$ with respect to $\mathrm{T}$, we have

$$
\mathrm{fx}_{0} \sqsupseteq \mathrm{fx}_{1} \sqsupseteq \mathrm{fx}_{2} \ldots
$$

By the condition (1) we have,

$d\left(T x_{n}, T x_{n+1}\right) \preccurlyeq a_{1} d\left(f x_{n}, f x_{n+1}\right)+a_{2} d\left(f x_{n}, T x_{n}\right)+a_{3} d\left(f_{x_{n+1}}\right.$, $\left.\mathrm{Tx}_{\mathrm{n}+1}\right)+\mathrm{a}_{4} \mathrm{~d}\left(\mathrm{fx}_{\mathrm{n}}, \mathrm{Tx}_{\mathrm{n}+1}\right)$

$$
\begin{aligned}
& \preccurlyeq a_{1} d\left(T x_{n-1}, T x_{n}\right)+a_{2} d\left(T x_{n-1}, T x_{n}\right)+a_{3} d\left(T x_{n},\right. \\
& \left.T x_{n+1}\right)+a_{4} d\left(T_{n}-1, T x_{n+1}\right) \\
& \preccurlyeq a_{1} d\left(T x_{n-1}, T x_{n}\right)+a_{2} d\left(T x_{n-1}, T x_{n}\right)+a_{3} d\left(T x_{n},\right. \\
& \left.T x_{n+1}\right)+a_{4}\left[d\left(T x_{n-1}, T x_{n}\right)+d\left(T x_{n}, T x_{n+1}\right)\right] \\
& \preccurlyeq\left(a_{1}+a_{2}+a_{4}\right) d\left(T x_{n-1}, T x_{n}\right)+\left(a_{3}+a_{4}\right) d\left(T x_{n}, T x_{n+1}\right) \text {. } \\
& \left(1-a_{3}-a_{4}\right) d\left(\operatorname{Tx}_{n}, \operatorname{Tx}_{n+1}\right) \preccurlyeq\left(a_{1}+a_{2}+a_{4}\right) d\left(\operatorname{Tx}_{n-1}, T_{n}\right) \\
& \preccurlyeq\left(\frac{a_{1+} a_{2}+a_{4}}{1-a_{3}-a_{4}}\right) \mathrm{d}\left(\mathrm{Tx}_{\mathrm{n}-1}, \mathrm{Tx}_{\mathrm{n}}\right) \text {. }
\end{aligned}
$$

Putting, $\mathrm{k}=\left(\frac{a_{1+} a_{2}+a_{4}}{1-a_{3}-a_{4}}\right)<1$.

We obtain,

$$
\mathrm{d}\left(\mathrm{Tx}_{\mathrm{n}}, \mathrm{Tx}_{\mathrm{n}+1}\right) \preccurlyeq \mathrm{kd}\left(\mathrm{Tx}_{\mathrm{n}-1}, \mathrm{Tx}_{\mathrm{n}}\right) .
$$

Thus, for $\mathrm{n} \in \mathrm{N}$, we have

$\mathrm{d}\left(\operatorname{Tx}_{\mathrm{n}}, \mathrm{Tx}_{\mathrm{n}+1}\right) \preccurlyeq \mathrm{kd}\left(\mathrm{Tx}_{\mathrm{n}-1}, \mathrm{Tx}_{\mathrm{n}}\right) \preccurlyeq \mathrm{k}^{2} \mathrm{~d}\left(\mathrm{Tx}_{\mathrm{n}-2}, \mathrm{Tx}_{\mathrm{n}-1}\right) \preccurlyeq \cdots \preccurlyeq \mathrm{k}^{\mathrm{n}}$ $\mathrm{d}\left(\mathrm{Tx}_{0}, \mathrm{Tx}_{1}\right)$.

Let $\mathrm{n}, \mathrm{m} \in \mathrm{N}$ with $\mathrm{m}>\mathrm{n}$. Then

$$
\begin{gathered}
\mathrm{d}\left(\mathrm{Tx}_{\mathrm{n}}, T \mathrm{Tx}_{\mathrm{m}}\right) \leqslant \sum_{i=n}^{m-1} d\left(T x_{i}, T x_{i+1}\right) \\
\approx \sum_{i=\mathrm{n}}^{m-1} k^{i} d\left(T x_{0}, T x_{1}\right) .
\end{gathered}
$$

Since, $\mathrm{k} \in[0,1)$, we have

$$
\mathrm{d}(\mathrm{Txn}, \mathrm{Txm}) \preccurlyeq \frac{-k^{n}}{1-k} \mathrm{~d}\left(\mathrm{Tx}_{0}, \mathrm{Tx}_{1}\right) \rightarrow \theta \text { as } \mathrm{n} \rightarrow \infty .
$$

We shall show that $\left\{\mathrm{Tx}_{\mathrm{n}}\right\}$ is a Cauchy sequence in $(\mathrm{X}, \mathrm{d})$.

For this, let $\mathrm{c}>>\theta$ be given.

Since, $c \in \operatorname{int}(\mathrm{P})$, then there exists a neighborhood of

$\theta, N_{s}(\theta)=\{y \in B:\|y\|<\delta\}, \delta>0$, such that

$\mathrm{c}+\mathrm{N}_{\delta}(\theta) \subseteq \operatorname{int}(\mathrm{P})$. Choose a natural number $\mathrm{N}_{1}$ such that $\left\|\frac{-k^{N_{1}}}{1-k} \mathrm{~d}\left(\mathrm{Tx}_{0}, \mathrm{Tx}_{1}\right)\right\|<\delta$.

Then for all $\mathrm{n} \geq \mathrm{N}_{1}$ we have that $\frac{-k^{n}}{1-k} \mathrm{~d}\left(\mathrm{Tx}_{0}, \mathrm{Tx}_{1}\right) \in \mathrm{N}_{\delta}(\theta)$.

Hence, $\quad \mathrm{c}-\frac{k^{n}}{1-k} \mathrm{~d}\left(\mathrm{Tx}_{0}, \mathrm{Tx}_{1}\right) \in \mathrm{c}+\mathrm{N}_{\delta}(\theta) \subseteq \operatorname{int}(\mathrm{P})$.

Thus, we have that for all $\mathrm{n} \geq \mathrm{N}_{1}$,

$$
\frac{k^{n}}{1-k} \mathrm{~d}(\mathrm{~T} \times 0, \mathrm{~T} \times 1)<<\mathrm{c} .
$$

By (3) and (4), it follows that

$\mathrm{d}\left(\mathrm{Tx}_{\mathrm{n}}, \mathrm{Tx}_{\mathrm{m}}\right)<<\mathrm{c}$ whenever $\mathrm{n} \geq \mathrm{N}_{1}$.

Hence, $\left\{\mathrm{Tx}_{\mathrm{n}}\right\}$ is a Cauchy sequence in $\mathrm{X}$.

Since, $\mathrm{TX} \subseteq \mathrm{fX}$.

Therefore, $\left\{\mathrm{fx}_{\mathrm{n}}\right\}$ is a Cauchy sequence in $\mathrm{fX}$. Since, $\mathrm{fX}$ is complete, then there exists $\mathrm{u}=\mathrm{fv}$ for

some $\mathrm{v} \in \mathrm{X}$ such that $\lim _{n \rightarrow \infty} f x_{n}=\mathrm{u}=\mathrm{fv}$.

Since $\left\{\mathrm{fx}_{\mathrm{n}}\right\}$ is a non-increasing sequence in $\mathrm{X}$, then

$\mathrm{fx}_{\mathrm{n}} \sqsupseteq \mathrm{fv}$ for all $\mathrm{n} \in \mathrm{N}$, then by (1) we have

$$
\begin{gathered}
d\left(T x_{n}, T v\right) \leqslant a_{1} d\left(f v, f x_{n}\right)+a_{2} d\left(f x_{n}, T x_{n}\right)+a_{3} d(f v, T v)+ \\
a_{4} d\left(f x_{n}, T v\right) .
\end{gathered}
$$

By the triangle inequality and (5) we have

$$
\begin{aligned}
\mathrm{d}(\mathrm{fv}, \mathrm{Tv}) & \preccurlyeq d\left(f v, f x_{n}\right)+d\left(f x_{n}, T x_{n}\right)+d\left(T x_{n}, T v\right) \\
& \preccurlyeq d\left(f v, f x_{n}\right)+d\left(f x_{n}, T x_{n}\right)+a_{1} d\left(f v, f x_{n}\right)+a_{2} d\left(f x_{n},\right. \\
& \left.T x_{n}\right)+a_{3} d(f v, T v)+a_{4} d\left(f x_{n}, T v\right) \\
& \preccurlyeq\left(1+a_{1}\right) d\left(f v, f x_{n}\right)+\left(1+a_{2}\right) d\left(f x_{n}, T x_{n}\right)+a_{3} d(f v, \\
& T v)+a_{4} d\left(f x_{n}, T v\right) \\
& \preccurlyeq\left(1+a_{1}\right) d\left(f v, f x_{n}\right)+\left(1+a_{2}\right)\left[d\left(f x_{n}, f v\right)+d\left(f v, T x_{n}\right)\right]+ \\
& a_{3} d(f v, T v)+a_{4}\left[d\left(f x_{n}, f v\right)+d(f v, T v)\right] \\
& \preccurlyeq\left(1+a_{1}+1+a_{2}+a_{4}\right) d\left(f v, f x_{n}\right)+\left(1+a_{2}\right) d(f v, \\
& \left.T x_{n}\right)+\left(a_{3}+a_{4}\right) d(f v, T v) .
\end{aligned}
$$


Hence, we have

$1-\left(a_{3}+a_{4}\right) d(f v, T v) \preccurlyeq\left(2+a_{1}+a_{2}+a_{4}\right) d\left(f v, f x_{n}\right)+\left(1+a_{2}\right) d(f v$, $\left.\mathrm{Tx}_{\mathrm{n}}\right)$.

$\mathrm{d}(\mathrm{fv}, \mathrm{Tv}) \preccurlyeq \frac{2+a_{1}+a_{2}+a_{4}}{1-\left(a_{3}+a_{4}\right)} \quad\left(\mathrm{fv}, \mathrm{fx}_{\mathrm{n}}\right)+\frac{1+a_{2}}{1-\left(a_{3}+a_{4}\right)} \mathrm{d}\left(\mathrm{fv}, \mathrm{Tx}_{\mathrm{n}}\right)$

Let $c>>\theta$ be given. Choose $\mathrm{k}_{1}, \mathrm{k}_{2} \in \mathrm{N}$ such that

$\left(\mathrm{fv}, \mathrm{fx}_{\mathrm{n}}\right)<<\frac{1-\left(a_{3}+a_{4}\right) \mathrm{c}}{2\left(2+a_{1}+a_{2}+a_{4}\right)}$ for each $\mathrm{n} \geq \mathrm{k}_{1}$, and

$\mathrm{d}\left(\mathrm{fv}, \mathrm{Tx_{n }}\right)=\mathrm{d}\left(\mathrm{fv}, \mathrm{fx_{n+1 }}\right)<<\frac{1-\left(a_{3}+a_{4}\right) \mathrm{c}}{2\left(1+a_{2}\right)}$, for each $\mathrm{n} \geq \mathrm{k}_{2}$.

Let $\mathrm{k}=\max \left\{\mathrm{k}_{1}, \mathrm{k}_{2}\right\}$.

Then, $\mathrm{d}(\mathrm{fv}, \mathrm{Tv})<<\frac{c}{2}+\frac{c}{2}=\mathrm{c}$.(by (4),(5) and (6)).

Since $\mathrm{c}$ is arbitrary, we get that

$\mathrm{d}(\mathrm{fv}, \mathrm{Tv})<<\frac{c}{m}$ for each $\mathrm{m} \in \mathrm{N}$.

Noting that $\frac{c}{m} \rightarrow \theta$ as $\mathrm{m} \rightarrow \infty$,

we conclude that $\frac{c}{m}-\mathrm{d}(\mathrm{fv}, \mathrm{Tv}) \rightarrow-\mathrm{d}(\mathrm{fv}, \mathrm{Tv})$ as $\mathrm{m} \rightarrow \infty$.

Since $P$ is closed, then $-d(f v, T v) \in P$.

Thus $\mathrm{d}(\mathrm{fv}, \mathrm{Tv}) \in \mathrm{P} \cap(-\mathrm{P})$.

Hence, $d(f v, T v)=\theta$.

Therefore, $\mathrm{fv}=\mathrm{T} \mathrm{v}$.

Then $f$ and $T$ have a coincidence point $v \in X$.

Remark 2.2. If we take $\mathrm{a}_{4}=0$ in the above Theorem 2.1, then we get the Theorem 2.3 of [8].

Remark 2.3. If we take $a_{1}=\lambda$ and $a_{2}=a_{3}=a_{4}=0$ in the above Theorem 2.1, then we get the following Corollary.

Corollary 2.4. Let $(X, \sqsubseteq)$ be partially ordered set and $(X, d)$ be a complete cone metric space over a solid cone $\mathrm{P}$. Let

$\mathrm{f}, \mathrm{T}: \mathrm{X} \rightarrow \mathrm{X}$ be two maps such that

$$
\mathrm{d}(\mathrm{Tx}, \mathrm{Ty}) \preccurlyeq \lambda \mathrm{d}(\mathrm{fx}, \mathrm{fy})
$$

for all $\mathrm{x}, \mathrm{y} \in \mathrm{X}$ for which $\mathrm{fx}$ and fy are comparable. Assume that $\mathrm{f}$ and $\mathrm{T}$ satisfy the following conditions:

(i). If $\left\{x_{n}\right\}$ is a non - increasing sequence in $X$ with respect to 巨such that $\mathrm{x}_{\mathrm{n}} \rightarrow \mathrm{x}$ as $\mathrm{n} \rightarrow+\infty$, then $\mathrm{x}_{\mathrm{n}} \sqsupseteq \mathrm{x}$ for all $\mathrm{n} \in \mathrm{N}$. (ii).f is weakly decreasing type A with respect to $\mathrm{T}$.

(ii). $\mathrm{X}$ is complete subspace of $\mathrm{X}$.

If $\lambda$ is a non-negative real number with $\lambda \in[0,1)$, then $\mathrm{f}$ and $\mathrm{T}$ have a coincidence point in $\mathrm{X}$.

\section{Acknowledgments}

The author thanks the referees for giving valuable suggestions to improve this paper.

\section{REFERENCES}

[1] M.Abbas and G.Jungck, Common fixed point results for non commuting mappings without continuity in cone metric spaces, J. Math. Anal. Appl. 341(2008) 416-420.

[2] I. Altun, G. Durmaz, Some fixed point theorems on ordered cone metric spaces, Rend. Circ. Mat. Palermo 58(2009) 319-325.

[3] I. Altun, B.Damjanović, D. Djorić, Fixed point and common fixed point theorems on ordered cone metric spaces, Appl. Math.Lett. 23(2012) 310-316.

[4] L.G.Huang, X. Zhang, Cone metric spaces and fixed point theorems of contractive mappings, J. Math. Anal.Appl. 332 (2)(2007)1468-1476.

[5] S.Janković, Z.Golubović, S.Radenović, Compatible and weakly compatible mappings in cone metric spaces, Math. Comput.Modelling 52(2010) 1728-1738.

[6] M. Rangamma and K.Prudhvi, Common fixed points under contractive conditions for three maps in cone metric spaces, Bulletin of Mathematical Analysis and Applications, Vol.4,Issue 1(2012),174-180.

[7] S.Rezapour and Halbarani, Some notes on the paper "cone metric spaces and fixed point theorem of contractive mappings “, J. Math. Anal. Appl., 345(2008), 719-724.

[8] W. Shatanawi, Some coincidence point results in cone metric spaces, Math. Comput. Modelling, Vol.55, Issue 7-8 (2012)2023-2028.. 